\title{
O ATIVISMO JUDICIAL: APROPRIAÇÃO DO TERMO NO DIREITO NORTE-
}

\section{AMERICANO}

\author{
Eneida Orbage de Britto Taquary ${ }^{1}$ \\ Catharina Orbage de Britto Taquary ${ }^{2}$
}

\begin{abstract}
RESUMO: Objetiva-se identificar o conceito de ativismo; diferenciar o ativismo judicial e transnacional; a apropriação do termo pela aérea jurídica e enumerar os casos apreciados pela Suprema Corte Norte-Americana. A problemática se refere à apropriação do termo no ordenamento jurídico, com a enumeração de casos apreciados pela Suprema Corte NorteAmericana, a partir da análise de Arthur Schlesinger Jr. A hipótese formulada decorre da modificação ocorrida nos sistemas normativos posteriores a Segunda Guerra Mundial determinando a jurisdição constitucional; a judicialização da política e de atos dos outros Poderes, mas também o ativismo jurídico nos países da Common Law e de origem continental.
\end{abstract}

PALAVRAS-CHAVES: Ativismo Jurídico Judicial. Ativismo Judicial Nacional. Ativismo Judicial Internacional. Suprema Corte Norte-Americana. Apropriação.

\section{JUDICIAL ACTIVISM: APPROPRIATION OF THE TERM NOT NORTH AMERICAN LAW}

\begin{abstract}
It aims to identify the concept of activism; differentiating between judicial and transnational activism; appropriation of the term by legal area and enumerate the cases appreciated by the North-American Supreme Court. Problematic refers to the appropriation of the term in legal order, with the enumeration of cases appreciated by the Supreme Court, from the analysis of Arthur Schlesinger Jr.. Hypothesis formulated follows from the modification that took place in the normative systems after World War II determining the constitutional jurisdiction; the judicialization of politics and acts of the other Powers, but also legal activism in Common Law and continental countries.
\end{abstract}

KEYWORDS: Judicial Legal Activism. National Judicial Activism. International Judicial Activism. Supreme Court of the United States. Appropriation.

\footnotetext{
${ }^{1}$ Doutora em Direito pelo Centro Universitário de Brasilia- UNICEUB, Mestre em Direito das Relações Internacionais pelo Centro Universitário de Brasília-UNICEUB e Mestre em Direito pela Universidade Católica de Brasília-UCB. Professora de Direito, com ênfase em Metodologia da pesquisa, Direito Penal e Processual Penal, Direito Internacional e Direitos humanos e humanitário. Delegada de Polícia Aposentada da Policia Civil do Distrito Federal. Tem experiência na área de Direito, Integrante do Observatório de Segurança Pública do Distrito Federal. Autora dos livros: Crimes Contra os Costumes; Tribunal Penal Internacional e a Emenda Constitucional no 45/2004; Temas de Direito Penal e Direito Processual e Proteção Internacional da Pessoa Humana.Professora de Direito Penal, Direito Processual Penal e Legislação Penal e processual Penal Especial. E-mail: eneidataquary@yahoo.com.br

2 Doutoranda em Direito e Políticas Públicas pelo UniCEUB. É bolsista da Coordenação de Aperfeiçoamento de Pessoal de Nível Superior - CAPES para Doutorado em Direito do Centro Universitário de Brasília - UniCEUB. É Mestre em Direito e Políticas Públicas pelo- UniCEUB e pela Universidad del Litoral de Santa Fe - Argentina. Fez intercâmbio em Santa Fé, Argentina para terminar seu Mestrado - Sanduíche como aluna da Universidad del Litoral - UNL. Foi Bolsista da Coordenação de Aperfeiçoamento de Pessoal de Nível Superior para Mestrado e Mestrado Sanduíche - CAPES. É bacharel em Direito pelo UniCEUB. Possui fluência em Alemão, Inglês e Espanhol. Tem proficiência em alemão e espanhol. Foi pesquisadora do Distrito Federal pela Fundação de Apoio à Pesquisa do Distrito Federal - FAP/DF para o curso de Doutoramento em Direito e Políticas Públicas do UniCEUB. E-mail: catharinaorbage@ yahoo.com.br
} 


\section{INTRODUÇÃO}

Analisa a apropriação do termo ativismo jurídico judicial no direito norteamericano, a partir dos estudos realizados pelo jornalista e historiador Arthur Schlesinger Jr., o qual classificou os Juízes dentre os que priorizavam em suas decisões o bem estar social e outros que decidiam apenas com base nos direitos previstos na legislação. Diferenciou juízes ativistas e conservadores, respectivamente.

Objetiva-se identificar o conceito de ativismo, diferenciando o ativismo judicial e transnacional, além de analisar a apropriação do termo pela aérea jurídica e ainda enumerar os casos apreciados pela Suprema Corte Norte-Americana que expressam essa tomada de decisão em prol dos Direitos Humanos.

A problemática se refere à apropriação do termo na área jurídica, com a enumeração de casos apreciados pela Suprema Corte Norte-americana, a partir da análise de Arthur Schlesinger Jr.

A hipótese formulada decorre da modificação que ocorreu nos sistemas normativos após a Segunda Guerra Mundial, os quais determinaram não somente a jurisdição constitucional, como também a judicialização da política e de atos dos outros Poderes, além do ativismo jurídico nos países da Common Law, de origem continental, e em vários países da América Latina e Africanos.

Em geral essas mudanças se deram em razão da transição de regimes políticos de extrema limitação dos direitos fundamentais pelas ditaduras militares para novos regimes liberais e com significativas mudanças de regimes políticos, expressos por meio de novas Constituições, que possuíam como fundamento a dignidade da pessoa humana e a responsabilização de indivíduos e de Estados na área penal, por crimes graves.

Nos sistemas do direito continental, como é exemplo o Brasil, antes da Segunda Guerra Mundial, as normas constitucionais não possuíam força normativa. Determinavam um regime de direitos e liberdades que deveriam orientar o legislador, sem, no entanto, interferirem na decisão judicial que se pautava exclusivamente na interpretação da lei. Logo, os direitos e liberdades somente eram protegidos se previstos na legislação e decorrentes da estrita interpretação da lei. 
Os efeitos atribuídos às normas constitucionais até então eram de simples programação para o legislador. Não eram utilizadas para tutela de direitos em juízo ou como fundamento de decisões judiciais.

Essa característica é evidenciada especialmente no sistema romano-germânico. A Constituição prevê direitos e liberdades que, todavia, não eram efetivados porque significavam apenas uma proposta de tutela que deveria ser desenvolvida pelo legislador ordinário, retirando daquele documento o seu significado verdadeiro de normas self executing (TAVARES.ROTHEMBERG. 2003. pp.136-137).

Diferentemente, nos sistemas da Common Law ao lado da Carta Política, foi constituído o regime de direitos e liberdades, atribuindo-se às normas constitucionais força normativa, inclusive limitando o poder dos legisladores e a alteração da Constituição, por meio de legislação ordinária. Esse sistema estabelece mecanismo de proteção da constituição, por intermédio da jurisdição constitucional. Os direitos e liberdades são protegidos independentemente de previsão em legislação infraconstitucional, por intermédio das decisões judiciais que se consolidaram como precedentes jurisprudenciais.

Ao lado das cartas de direitos surgidas no bojo das constituições, uma necessidade surgiu também no tocante a reformulação das formas tradicionais de interpretação. A interpretação literal da lei e a atividade jurisdicional foram modificadas para dar lugar a uma interpretação não mais baseada na extração da vontade do legislador, mas numa escala axiológica, observando princípios relevantes para a decisão razoável, atendendo os anseios da sociedade, com base em novas técnicas, como a da ponderação, e nos princípios que expressam valores comuns da humanidade e ao mesmo tempo dos Estados Democráticos, que os tem como fórmula política, jurídica e social da Constituição Federal.

A proteção da constituição pelos mecanismos constitucionais instigou a irradiação de efeitos das suas normas e determinou uma maior atividade jurídica, não apenas do Poder Judiciário, mas dos Poderes Executivo e Legislativo.

Nos sistemas jurídicos de tradição da Common Law essa atividade foi desempenhada prioritariamente pelos Juízes que consolidaram os precedentes jurisdicionais, tornando a lei expressão viva da pretensão social e individual, enquanto no sistema romano-germânico além do ativismo legislativo, incrementado pelas Constituições Democráticas, determinando uma excessiva produção de leis, o ativismo judicial foi determinante para a proteção dos direitos 
humanos e se desenvolveu por meio dos sistemas normativos estatais, internacionais e ainda pelos sistemas de cooperação jurídica entre os Estados, por meio da ratificação dos tratados multilaterais.

\section{O DESENVOLVIMENTO DO ATIVISMO JURÍDICO}

O ativismo legislativo e judicial desenvolveu-se no cenário estatal, internacional e transnacional, por meio das decisões proferidas pelos juízes integrantes dos sistemas normativos de proteção regional e internacional, bem como das opiniões consultivas decorrentes das interpretações das normas internacionais.

No âmbito nacional, o ativismo judicial é entendido como a atividade jurisdicional que protege direitos humanos ou humanitários, independentemente de previsão no ordenamento jurídico estatal ou de posições contramajoritárias de determinada corte, a qual houve a dedução de um conflito subjetivo de interesses e de um conflito normativo. É a tomada de decisão em prol da proteção do indivíduo, com a interpretação pro homine.

É evidenciado quando não se tem aporte jurídico para conceder a proteção do direito ou quando já existem precedentes que caracterizam opinião majoritária de uma determinada Corte no sentido de não proteção do direito humano. Pode ocorrer ainda quando a posição contramajoritária não realiza a tutela dos direitos envolvidos na lide. O juiz é um legislador implícito.

No âmbito transnacional o ativismo jurídico é um fenômeno que vem interferindo no âmbito das jurisdições domésticas, oriundos de decisões das Cortes Internacionais e das Cortes Estrangeiras. As Cortes Internacionais nascem no bojo de Tratados, enquanto as Cortes Estrangeiras estão contidas na estrutura do sistema jurídico que se adota; as funções atribuídas ao Estado e seus poderes instituídos e a proteção dos direitos fundamentais do indivíduo.

O ativismo judicial transnacional é o gênero do ativismo do qual decorre o ativismo internacional e o estrangeiro. O internacional se caracteriza como uma atividade que contém o ativismo que é realizado pelas Cortes Internacionais, criadas no âmbito do sistema onusiano ou decorrente de Tratados multilaterais. 
O estrangeiro se evidencia quando há a circulação dos precedentes de Cortes Constitucionais, no âmbito da jurisdição doméstica, ou de decisões estrangeiras, quando analisam questões que envolvem mais de dois países; mais de dois governos soberanos, ou que tenham por objeto direitos humanos ou humanitários.

O fenômeno tem sido evidenciado também por meio da judicialização global, que tem sua gênese na criação de cortes internacionais $A d$ Hoc ou permanentes, e no estabelecimento de tribunais arbitrais, que tem por objeto a discussão de questões de direitos humanos e outras, inclusive de fundo comercial.

O momento histórico em que o ativismo jurídico transnacional desponta relaciona-se com as relações, ao menos no plano teórico igualitárias, surgidas após a Segunda Guerra Mundial, deixando de lado as relações antes estabelecidas com fundamento no binômio: dominador e dominado, ou nas relações de animosidade entre o Leste Europeu e o Ocidente, fazendo surgir novos atores internacionais estatais e determinando a participação nas relações comerciais e na política internacional de novos países e de outros que emergiram no plano mundial, em face de novo paradigma econômico (VAISSE. 2009. pp.269-274).

Entende-se, portanto, como ativismo judicial transnacional internacional a atividade jurisdicional levada a efeito pelos juízes das Cortes Internacionais, que têm como objeto a proteção do indivíduo, sem a intermediação do Estado, visando tornar efetivos os direitos humanos, não reconhecidos ou não protegidos pelo Estado.

Esses Direitos podem ser extraídos mediante o processo de interpretação da Carta de Direitos integrantes e estruturantes do sistema em que se litiga, com força normativa e cogente estruturada, não em mera interpretação cognoscitiva do juiz, mas também na consciência jurídica formal e material, expressas pela interpretação universalista do direito que se obtém da interpretação da lei, mediante a valoração dos postulados jurídicos, políticos e morais, que tornam a decisão socialmente aceitável como justa e acertada.

Os efeitos do ativismo atingem tanto países da Common Law como da Civil Law, com a diferença básica que os primeiros admitem a construção da norma a partir da decisão judicial, fundamentada ou não nos precedentes, já que eles podem ser modificados ante um novo caso em exame, bem como nas formas de interpretação teleológica ou integração das normas jurídicas que devem servir a resolver o caso atual, naquele contexto histórico-políticosocial. 
Nos sistemas de origem da Common Law, o ativismo judicial se afigura como uma constante, na construção das normas jurídicas por meio dos precedentes jurisprudenciais e novas decisões revogatórias, inclusive de precedentes anacrônicos, enquanto no sistema da Civil Law. O limite da jurisprudência é estabelecido pelo Poder Legislativo, que fixa a competência da atuação judicial, criando óbices na construção da norma.

Note-se, entretanto, que na atualidade verifica-se certa confluência na criação do direito nos dois sistemas, pela premência em se proteger os direitos humanos, decorrentes de fatores sociais, políticos e econômicos, dinâmicos e que estão exigindo a atenção das autoridades nacionais e internacionais.

Todavia, apesar do ativismo ter sido sentido inicialmente na Europa, ele foi desencadeado décadas depois nas Américas, na África e em países asiáticos e o estudo empírico do termo foi utilizado inicialmente nos Estados Unidos, a partir da análise das decisões dos magistrados da Suprema Corte Norte-Americana e do comportamento de cada um deles, frente à decisão, realizada pelo jornalista e historiador Arthur Schlesinger Jr..

\section{O TERMO ATIVISMO JUDICIAL NOS ESTADOS UNIDOS COMO EXPRESSÃO DO COMPORTAMENTO DOS JUÍZES DA SUPREMA CORTE}

O termo ativismo tem origem nos Estados Unidos, motivando a utilização da expressão em sentido positivo ou negativo em relação às decisões da Corte Constitucional Norte-Americana. O sentido positivo será vinculado à decisão que concedeu o direito, e negativa a que não o concedeu.

A análise da expressão nos Estados Unidos encontra coincidência com a expressão utilizada no Brasil, ao se atribuir ao Supremo Tribunal Federal um papel ativista, para significar um afastamento do positivismo formalista e engajar-se na atuação voltada para a atividade criativa, objetivando o fortalecimento e promoção de valores nas suas decisões, que têm alcance social por tratar de temas controvertidos, de interesse da sociedade, e que se impõem ao juiz na presença da omissão legislativa ou de legislação inconsistente para proteger direitos humanos e humanitários (LOCKART. KAMISAR. CHOPER. FALLON. 1996. pp. 657-752). 
É construído politicamente, evidenciando um comportamento dos juízes, que não decidem unilateralmente, mas que procuram superar deficiências dos sistemas, como a imprecisão de direitos previstos nas Constituições, a falta de agilidade dos Poderes Legislativos e Executivo em construir juntos políticas públicas e alterar a legislação de forma a considerar as realidades atuais da sociedade e ainda a modificação de decisões que constituíam precedentes jurisprudenciais, mas que se tornaram anacrônicos e eram destinados a uma sociedade não mais existente.

A expressão "ativismo judicial” aparece pela primeira vez nos Estados Unidos em matéria jornalística intitulada The Supreme Court: 1947, publicada na Revista Fortune, vol. XXXV, no 1, no mês de Janeiro de 1947, assinada pelo historiador Arthur Schlesinger Jr., que também era jornalista (SCHLESINGER Jr.. 1947. p. 73).

$\mathrm{O}$ artigo trazia três importantes ideias. A primeira a de que uma Corte Constitucional, pela importância das matérias que julga e da repercussão de suas decisões na sociedade, sempre estaria sujeita as críticas em face de suas motivações e de fatores endógenos ou exógenos que poderiam influenciar uma decisão. Os julgadores as deveriam assimilar e refletir para novamente decidir (KMIEC. 2004. pp. 1441-1477).

A segunda, a de que analisar as questões que dividem os juízes em suas decisões seria importante para determinar a atuação de cada um deles, porque a nação seria moldada pelas suas decisões e pela repercussão no tempo (KMIEC. 2004. pp. 1441-1477).

A terceira ideia se referia ao perfil dos juízes da Suprema Corte, atribuindo-lhes, segundo cada atuação, a característica de serem ativistas, porque preocupados com a promoção do bem comum (KMIEC. 2004. pp. 1441-1477).

A partir das ideias acima, o referido historiador classificou os nove juízes da Suprema Corte Americana, todos nomeados pelo ex-presidente Roosevelt, em quatro categorias: (i) juízes ativistas com ênfase na defesa dos direitos das minorias e das classes mais pobres (Hugo Black; Willian O. Douglas); (ii) juízes ativistas com ênfase nos direitos de liberdade(Frank Murphy Wiley Rutlege; (iii) juízes campeões da autorrestrição (Felix Frankfurter, Robert H. Jackson e Harold Burton); (iv) juízes que representariam o equilíbrio de forças (balance of powers - Stanley Reed e Chief JusticeFred Vinson) (McWHINNEY. 1956. pp. 170-185; HORWITZ. 1998. p. 114; BURNS. 2009. p. 167). 
Com a classificação realizada por Schlesinger Jr. definia-se dois grandes grupos: os dos ativistas representados por Hugo Black e os autorrestritivos, representados por Felix Frankfurther, sendo que os juízes Fred Vinson e Stanley Reed ora decidiam como ativistas, ora como restritivos, determinando certo equilíbrio na Corte Vinson. Esse equilíbrio teria seu fim com a morte dos juízes Murphy e Rutledge. (SCHLESINGER Jr.. 1947. p. 73).

Observe-se ainda, segundo o pensamento de Schlesinger, que o ativismo judicial se opunha à autorrestrição judicial, porque os primeiros acreditavam que deveriam atuar com o objetivo de promover as liberdades civis e os direitos das minorias, dos hipossuficientes, ainda que tivessem que corrigir os erros do legislador. Já para os segundos, as responsabilidades de cada órgão estavam definidas por lei e, portanto, não caberia ao Judiciário interferir nos problemas políticos, mas agir consoante a lei e respeitando a vontade do legislador (SCHLESINGER Jr. 1947, p. 75-77).

A discussão entre os juízes ativistas e os antiativistas restringia-se a definir o papel e a função do Judiciário na Democracia. Esse conflito era marcado substancialmente pelas ideias de Hugo Black e Felix Frankfurter, que debatiam continuamente se a Constituição e a Bill of Rigths Norte-americanas criavam forma de governo limitado, e que, portanto cabia ao Judiciário tornar efetivos os direitos e as liberdades constitucionais, ou ao revés, ao Judiciário competia apenas o dever de resguardar os direitos e liberdades previstos no Bill of Rights, que estavam excluídos de qualquer ingerência do Congresso. (SCHLESINGER Jr.. 1947. p. 73).

Os juízes Black e Frankfurter criaram duas posições antagônicas em relação às suas decisões e que ainda hoje são importantes na medida em que se analisam a questão da jurisdição constitucional, que será discutida abaixo, bem como o papel do Judiciário nas denominadas Novas Democracias. Para eles, o papel do Judiciário estava relacionado estritamente com a possibilidade ou não de reescrever uma lei, ou interpretá-la de forma extensiva ou até mesmo contrariando a sua literalidade (SCHLESINGER Jr.. 1947. p. 73)

Nesse contexto, Black admitia que a carta de direitos humanos deveria ser interpretada para garantir sua promoção e a tutela dos direitos e liberdades ali previstos, independentemente da literalidade da lei. (SCHLESINGER Jr.. 1947. p. 73).

Frankfurter defendia que não havia supremacia do Judiciário sobre os outros Poderes e que por isso os juízes deveriam decidir casos a eles apresentados, sem, todavia, criar a estrutura normativa que era função do governo e dos legisladores, evitando usurpar o poder

Rev. de Direitos Humanos em Perspectiva | e-ISSN: 2526-0197| Brasília | v. 3 | n. 1 | p. 18 - 38 | Jan/Jun. 2017 
depositado nos legisladores, agindo, não somente, com cautela e com restrição nos casos de apreciação de direitos e liberdades individuais, mas também nos casos de judicial review (USA. SUPREME COURT. Trop v. Dulles. 2015).

As ideias do grupo denominado de juízes ativistas e os outros de juízes da autorestrição judicial, consoante à classificação de Schlesinger, expressavam um pensamento de tradição liberal comum, mas as divergências se restringiam ao papel da Suprema Corte em especial sobre a intervenção daquela Corte Constitucional nas questões políticas. (SCHLESINGER Jr.. 1947. p. 73).

O estudo detalhado de Arthur M. Schlesinger Jr. não passou despercebido por outros estudiosos do tema que o acusaram de superficialidade, de não ter definido o que era ativismo e ainda de que teria se apropriado do termo de seu colega de Harvard, Thomas Reed Powel, apesar de ter dado publicidade ao tema e de ter levantado o questionamento sobre a jurisdição constitucional, enquanto instrumento de proteção da própria constituição e da efetividade de direitos e liberdades fundamentais, proporcionadas por decisões judiciais (THOMAS REED POWELL. 2015).

Todavia, em que pesem as críticas realizadas contra o estudo de Schlesinger, denotase que o ativismo judicial foi designado como uma atuação proativa do Judiciário em rever as leis quando houver atentado aos direitos e liberdades humanas e a democracia NorteAmericana. (SCHLESINGER Jr.. 1947. p. 73).

Aos ativistas caberiam as decisões de caráter político e a construção do direito, sempre voltados para o sentido de justiça social, de bem estar da coletividade e em especial das pessoas hipossuficientes, enquanto para os juízes antiativistas, que não criavam o direito, caberia a responsabilidade pela decisão dos casos e deveriam ser restritos ao interpretar a constituição, em especial quando implicar revisão dos atos do governo e do legislativo, pois quem deve revisar as leis é o próprio legislativo. (SCHLESINGER Jr.. 1947. p. 73).

Schlesinger, apesar de não negar o ativismo judicial ou então não entender que algumas vezes ele seria necessário, manifestou-se taxativamente como partidário da ideia de que o Judiciário não poderia ter seus poderes expandidos. Ao revés, o Judiciário estaria sujeito aos limites impostos pelo legislador e somente o Poder Legislativo teria o poder de modificar ou criar as leis. (SCHLESINGER Jr.. 1947. p. 73). 
Portanto, observa-se que o conceito de ativismo extraído das ideias de Schlesinger deriva de três fatores: a legitimidade do órgão que a realiza; a técnica de interpretação utilizada e a manutenção da força normativa da constituição. (SCHLESINGER Jr.. 1947. p. 73).

Em relação ao primeiro fator, a legitimidade do órgão que realiza o ativismo judicial é o objeto de discussão e não a consistência jurídica da decisão do Poder Judiciário, em regra, praticado pelas Cortes Constitucionais (no caso Norte-Americano, a Suprema Corte) e no caso brasileiro pelos Tribunais Superiores- Supremo Tribunal Federal e Superior Tribunal De Justiça (TRINDADE; MORAIS. nº 53. 2011).

O segundo fator é caracterizado por uma interpretação extensiva e teleológica das normas constitucionais, de forma a tornar efetivo os direitos e liberdades fundamentais, esclarecendo o conteúdo das normas e corrigindo os erros e omissões do legislador, possibilitando a criação da lei por meio do precedente ou, no caso do Brasil, também por meio da súmula vinculante. (TRINDADE; MORAIS. nº 53. 2011).

O terceiro fator caracterizado pela manutenção e proteção da fórmula política contida na Constituição pelos mecanismos da jurisdição constitucional. (TRINDADE; MORAIS. n $^{\circ}$ 53. 2011).

Os fatores extraídos do estudo realizado por Schlesinger sobre o ativismo demonstram semelhança com o sistema da Civil Law, que se caracteriza pela produção do direito pelo Legislativo, que fala e age em nome da maioria da sociedade, que representa, estabelecendo os limites da interpretação da lei pelo Juiz e atribuindo força normativa à constituição, nos limites estabelecidos pelo poder político.

\section{OS PRECEDENTES DO ATIVISMO JUDICIAL NA SUPREMA CORTE NORTE- AMERICANA}

Além da definição de ativismo que se estabelece a partir das ideias de Schlesinger, outra análise importante na definição do conceito e que merece acolhida são os precedentes históricos do ativismo judicial (GREEN. 2009. p. 1195) e que se constitui das decisões proferidas nos períodos Marshall (1801 a 1835); no período denominado Lochner, (1905 a 1937), bem como no período da Corte Warren, presidida por Earl Warren, no período de 
1953 a 1969, conhecidos, respectivamente como o período tradicional, o de transição e o moderno (SCHWARTZ.1996. pp. 118-119).

O período tradicional é marcado pela supremacia da Constituição sobre qualquer outra lei e ainda pela interpretação voltada para o aspecto substancial da Constituição. Os seus princípios passam a ter força vinculante, não mais apenas como um parâmetro a ser seguido pelo legislador ordinário. Todavia, ainda se percebe o ativismo negativo em detrimento dos indivíduos, como no caso Dred Scott v. Sandford. (SCHWARTZ.1996. pp. 118-119).

O período de transição é marcado pela intervenção política nas decisões da Suprema Corte Norte-Americana, evidenciado pela crise econômica, com a quebra da bolsa, que determinou medidas econômicas graves pelo então presidente Franklin Roosevelt, que assumira o poder em 1933, mas que foram invalidadas pela Suprema Corte com fundamento nos princípios do devido processo e na cláusula do comércio. (ROOSEVELT. 1962. pp. 7389).

Somente no segundo mandato, período de 1937 a 1940, que a Corte se rendeu às medidas econômicas de Roosevelt, ao adotar a chamada rational basis test, presumindo constitucionalidade das leis de intervenção no domínio econômico (ROOSEVELT. 1962. pp. 73-89).

$\mathrm{O}$ ativismo estadunidense se encontra na fase moderna e decorre das decisões proferidas ainda no governo Roosevelt, a maioria de caráter econômico, e que acabaram por ser suplantadas pelos direitos civis. Essa fase do ativismo é marcada pela interpretação da Constituição como norma irradiadora de direitos e liberdades, inclusive como forma de superar as deficiências do processo de escolha política dos deputados e senadores (SCHWARTZ. 1996. pp. 255-258).

Cada um desses períodos é marcado pela análise e julgamento de uma questão jurídica importante, evidenciando a atividade jurisdicional, que se denomina positiva quando prioriza os direitos fundamentais, e negativa quando as decisões, em face de interpretação restrita, priorizam a Carta Política em detrimento do Bill of Rights.

No período tradicional, iniciado em 1787, surge a primeira expressão do controle judicial de constitucionalidade das leis com a promulgação da Constituição e o ativismo judicial norte-americano é marcado pela supremacia das leis constitucionais, de forma que 
seus princípios não seriam apenas regras programáticas para o legislador, mas possuiriam força normativa e teriam hierarquia sobre outras leis. (SCHWARTZ. 1996. pp. 118-119).

O ativismo judicial ficou caracterizado na Suprema Corte Norte-Americana pelo controle de constitucionalidade das leis, sob a presidência de John Marshall, nomeado pelo Presidente John Adans, como Chief of Justice no período de 1801 a 1835 . Ele demonstrou aos seus pares o importante papel das decisões da Corte no cenário sociopolítico (USA. SUPREME COURT. 2015).

A desafiadora decisão do juiz Marshall, no caso Marbury versus Madison, em 1803, obviamente sem os contornos hoje existentes, mas num período muito rico da história da jurisprudência da Suprema Corte Norte-americana, contribuiu de forma inesquecível para a consolidação do princípio da supremacia do Judiciário para exercer o controle da constitucionalidade das leis.

O caso mencionado refere-se à nomeação para o cargo de juiz de paz de Willian Marbury, em 1801, para o Distrito de Columbia, nos últimos dias do governo de Adans. Sua posse foi negada por James Madison, secretário do governo, seguindo instruções do presidente Jefferson, que derrotara Adams nas urnas. Marbury então impetrou o writ of mandamus contra Madison, utilizando a Seção 13 do Judiciary Act de 1789, entendendo que a Suprema Corte tinha a competência originária para julgar mandamus contra autoridades públicas, como secretários de estado do governo federal. (SCHWARTZ.1996. pp. 118-119).

Marshall, em decisão política, ressaltou a obediência aos preceitos constitucionais, afirmando que o ato de Madison era ilegal e, como tal, não poderia ser convalidado frente à Constituição, como lei suprema e imodificável por leis ordinárias. Não afrentou o fundamento jurídico apontado por Marbury como objeto do seu pedido, a violação da Seção 13 do Judiciary Act de 1789, porque a Corte Suprema não tinha competência originária para rever atos do Executivo ou Legislativo, somente em sede recursal. (SCHWARTZ.1996. pp. 118119).

Mas não menos importante para demonstrar o ativismo judicial da Suprema Corte foi a decisão no caso Dred Scott versus Sandford, apesar de ter efeitos inversos ao caso Marbury, posto que fundamentou a decisão em antivalores que estavam sendo discutidos e construídos na esfera do legislativo, como o racismo. 
O caso tem por objeto uma demanda proposta por Dred Scott, perante a Corte Estadual do Missouri, onde peliteava a sua liberdade. Ele era escravo do major do Exército John Emerson, e o acompanhava em todos os territórios onde e deveria servir. Em alguns estados a escravidão era proibida, em especial em 1834, em Rock Island, no Estado de Illinois, e ainda em 1836, no Fort Snelling, localizado em Wisconsin, decorrente esta última de lei federal, intitulada de Compromisso do Missouri (USA. SUPREME COURT. 2017).

A demanda proposta por Dred Scott tinha como fundamento fático e jurídico o direito adquirido à liberdade que ele teria quando acompanhou o major Emerson ao Estado de Illinois, no período de 1834 a 1836, e no território de Wisconsin, no período de 1836 a 1838, quando foi alforiado. Todavia, a viúva reusava-se a libertá-lo. A princípio Dred Scott obteve êxito, mas na Suprema Corte do Missouri perdeu a demanda, sendo ela submetida à Suprema Corte, por entender que a questão era federal. (SCHWARTZ.1996. pp. 118-119).

A decisão foi proferida na Suprema Corte pelo Chief Justice Roger Taney, que não enfrentou o direito à liberdade de Dred Scott, mas seu voto teve como fundamento se ele era cidadão americano e se possuía direito de demandar perante os tribunais do país, porque esse direito somente era conferido ao povo dos Estados Unidos e aos cidadãos que compunham o povo soberano e que detinham direitos e liberdades. (SCHWARTZ.1996. pp. 118-119).

O juiz Taney considerou que os negros da raça Africana não eram cidadãos porque tinham sido trazidos para os Estados Unidos e vendidos e mantidos como escravos, e afirmou ainda o direito de propriedade, como constitucionalmente previsto, sobre os escravos, que eram, segundo Taney "uma classe de seres humanos subordinada e inferior, que tinha sido subjulgada pela raça dominante, e mesmo que emancipados, ainda permaneceriam sujeitos a sua autoridade" (USA. SUPREME COURT. 2017).

$\mathrm{O}$ voto ainda tinha por objeto a natureza jurídica do direito em tela; se ele poderia ser discutido em âmbito federal e se poderia também ser discutido no âmbito das jurisdições estaduais, motivando a decisão de que o Compromisso de Missouri era inconstitucional. Ademais, o voto consolida a claúsula do devido processo legal como restrição às ações do governo que tivessem por fim a limitação do direito de propriedade e das liberdades individuais. Impôs ainda a decisão de que o ativismo, sob o aspecto de que a Constituição Norte-americana deveria ser interpretada no contexto histórico do fato, e que segundo esse, os negros eram uma raça inferior e propriedade do homem livre, e logo poderiam ser comercializados (FINKELMAN, 2006. p. 24-33). 
O ativismo da Suprema Corte reside no fato de que, com o voto do Juiz Taney, a questão que deveria ser resolvida pelo Congresso foi tratada como mera questão judicial, poupando os que tinham a perder politicamente, instigando e desencadeando a Guerra Civil, tornando evidente a cisão entre escravogratas e antiescravagistas. (FONTE).

As consequências desencadeadas pela decisão a Suprema Corte, no caso Dred Scott, revelam que o ativismo judicial foi manipulado por questões políticas, não permitindo ao Congresso deliberar sobre o escravagismo e sobre a possibilidade de os estados estabelecerem direitos e liberdades em suas circunscrições, impedindo novas discussões sobre os temas abordados, bem como impedindo que fossem analisados os efeitos da decisão naquele contexto.

Apesar de terem sido fidedignos ao texto constitucional, impedindo o poder de reformar a Constituição ou modificar o sentido de cidadania e de propriedade, no caso de escravos negros, não prestigiou outros valores que apesar de não contidos na lei constitucional, eram prestigiados nas leis estaduais como valores, o que poderia ter levado a Corte a corrigir a Constituição (SUSTEIN. 2000. pp. 64-89).

Outra expressão do ativismo Norte-americano é encontrada, agora na denominada era Lochner, no caso submetido a julgamento conhecido como Lochner v. New York, de 1905. Foi precedido pela análise do devido processo legal substantivo no caso conhecido como Mugler v. Kansas, que tinha por objeto a condenação de Mugler por descumprir a regra de proibição de venda de bebidas tóxicas, exceto para fins médicos, mecânicos, científicos, e regular a fabricação e venda dos mesmos para fins de isenção, bem como a construção de uma cervejaria na cidade de Salina, Saline Country, no Kansas (WOLFE. 1994. pp 4-10).

O caso foi decidido pela Suprema Corte Norte-americana, que entendia ter havido excesso no poder de polícia das autoridades do Kansas quando condenaram Mugler não apenas pela produção de cerveja, mas ainda pela desapropriação e demolição do estabelecimento, alegando ofensa à saúde; à segurança e à moral da comunidade. A condenação foi exagerada, segundo a decisão, porque para perder a propriedade deveriam ter sido observados os preceitos constitucionais referentes ao devido processo (USA. SUPREME COURT. 2017 ).

No caso Locker versus New York, a Suprema Corte examinou a limitação imposta pelo Estado de Nova York na jornada de trabalho dos padeiros, que foi fixada em 10 horas 
diárias e 60 horas semanais. O objeto central da questão refere-se à inconstitucionalidade ou não da legislação ordinária por haver excedido sua competência em razão da matéria, interferindo na liberdade de contratação de empregados e ainda nas cláusulas contratuais da relação de emprego (USA. SUPREME COURT. 2017).

Entendeu que a legislação do Estado de Nova York não podia interferir nos direitos de contratação dos empregados e em suas cláusulas contratuais, porque a matéria não era de sua competência-; o direito de contratação entre o empregador e o empregado havia sido violado; e ainda o número de horas que o empregado poderia trabalhar conflitava com a liberdade do indivíduo protegida pela XIV Emenda da Constituição Federal Americana. (USA. SUPREME COURT. 2017).

A declaração de inobservância do devido processo legal substantivo no caso acima tornou evidentes os votos dissidentes dos juízes John Marshall Harlan e Oliver Holmes. O primeiro entendeu que não houve deferência no exame da legislação nova-iorquina, e logo ao povo que por ela era representado, e ainda que decisões que tivessem por objeto políticas públicas de saúde ou outras que visassem o bem estar social deveriam ser precedidas de análise do impacto econômico e sociopolítico realizados pelo legislador estadual novaiorquino.

O segundo, que a decisão atingia a competência legal do Legislativo em normatizar políticas públicas, e ainda desprezava o Executivo em sua capacidade de estabelecer essas políticas a partir de um plano nacional econômico, que não poderia ser modificado por vontade da Suprema Corte.

As decisões da Suprema Corte, sob a presidência de Lochner, eram baseadas na promoção e tutela dos direitos individuais, com fundamento no devido processo legal substantivo, mas acabou por se caracterizar, em sua totalidade, contrárias à política do Governo e favorecedora das elites dominantes, julgando inconstitucionais as políticas públicas instituídas inclusive pelo governo federal, denominado New Deal. Essa tendência de não interferência estatal nas relações privadas ficou conhecida como política judiciária de contenção ( self-restraint) (MATTOS. 2004. pp. 11-17).

$\mathrm{Na}$ Corte Warren o ativismo foi tão representativo que Earl Warren foi objeto de um manifesto, no qual se propugnava pelo seu impeachment, em especial pelas decisões que tornava obrigatório a convivência de negros e brancos nas escolas e logradouros públicos, 
refletida pelo julgamento do caso Brown v. Board Education onde se declarou a inconstitucionalidade da segregação racial nas escolas do sul dos Estados Unidos, com base no principio da igualdade, previsto na Décima Quarta Emenda da Constituição Norteamericana. Segundo a decisão, as escolas deveriam adotar regimes integrados para brancos e negros, superando a doutrina da separated but equal (LOCKART; KAMISAR; CHOPER; FALLON JR., 1996. pp. 1160-1180).

O ativismo da Suprema Corte ficou novamente evidenciado com o julgamento de vários casos tendo como objeto o princípio do devido processo legal, quando participavam da Corte Warren os Juízes Byron R. White e Arthur Goldenberg. Dentre eles destacam-se: a) Mapp v. Ohio, a Suprema Corte pacificou o entendimento de que o mandado de busca e apreensão somente poderia ser emitido por autoridade judicial, e afastou a utilização de provas obtidas por meios ilícitos, em face do devido processo legal, preconizado pela Décima Quarta Emenda da Constituição Norte-Americana (US SUPREME COURT. 2017); b) Fay v. Noia, 1963, a Corte reconheceu que as condições da sociedade contemporânea não comportavam condenação criminal baseada em provas colhidas por meio de uma confissão possivelmente forçada, também por força da Emenda referida (USA. SUPREME COURT. 2017); c) In Re Gault et al, datado de 1967, a Suprema Corte decidiu que é aplicável o devido processo legal aos menores submetidos a processo criminal, como a observância de cautelas específicas relacionadas ao comportamento peculiar da criança e do adolescente e o direito do advogado (LOCKART; KAMISAR; CHOPER; FALLON JR. 1996. pp. 1160-1180).

A assistência judiciária foi prestigiada nos casos Gideon v. Wainwright, em 1963, quando a Corte de Warren definiu que os acusados perante tribunais estaduais teriam direito a assistência judiciária patrocinada pelo Estado, caso não tivessem condições de contratar advogado, e Miranda v. Arizona, em 1966, que garantiu o direito de proteção contra a autoincriminação, objeto da Quinta Emenda, proibindo o constrangimento na produção das provas e regras nos interrogatórios policiais (USA. SUPREME COURT. 2017).

O direito ao voto foi objeto dos casos Gray v. Sander, (1963) e Reynolds v. Sims (1964). Neles se reconheceu o direito à plena liberdade de voto, o que gerou a cláusula: um homem, um voto (one man, one vote). No caso United States v. Mississipi, (1965), a Suprema Corte reconheceu o direito de voto de negros no estado do Mississipi (USA. SUPREME COURT. 2017). 
Além do direito às convicções políticas, no caso Bond v. Floly, 1966, a Suprema Corte assegurou direitos dos americanos por suas convicções políticas, decretando a inconstitucionalidade de ato praticado pela Assembleia da Geórgia, que negou posse ao deputado Bond por ter criticado a Guerra do Vietnã (USA. SUPREME COURT. 2017).

Em matéria política, é significativo o caso Baker v. Car, datado de 1962, no qual a Suprema Corte Americana passou a admitir que a ordenação dos distritos eleitorais fosse matéria de competência do Poder Judiciário, deixando de ser vista como questão política, logo sujeita a controle judicial.

O caso New York Times Co. v. Sullivan retrata a liberdade de expressão, quando houve reversão da condenação sofrida pelo jornal mencionado por ter publicado matéria na qual se solicitava voluntário para patrocinar a causa em defesa de Martin Luther King, e por ter imputado aos policiais do Estado do Alabama condutas impróprias contra o movimento dos direitos civis dos afroamericanos (USA. SUPREME COURT. 2017).

Ainda retratando o ativismo acerca da liberdade de expressão, tem-se o caso Brandenburg v. Ohio, cuja decisão teve como objeto a absolvição de um líder da Klu Klux Klan que defendera a subversão da ordem pela força e violência, motivando sua acusação, que fora considerada improcedente porque não tinha havido a finalidade de praticar crimes e a manifestação do pensamento não caracterizava uma incitação (USA. SUPREME COURT. 2017).

A Corte Warren ativista foi substituída pela Corte Burger, quando Burger assumiu a sua presidência, quando da aposentadoria de Warren. Nomeado por Nixon, a Corte continuou com seu papel ativista até 1986, como se depreende do julgamento do caso Roe v. Wade, que autorizou o aborto nos casos de riscos para a gestante, destacando que não poderia ser criminalizado sem exceções (USA. SUPREME COURT. 2017).

A Suprema Corte Norte-Americana somente foi conservadora em sua jurisprudência a partir da nomeação do Juiz William H. Rehnquist. O caso Bowers v. Hardwich, de 1986, tem por objeto a legislação da Geórgia que criminalizou a sodomia, isto é a autodeterminação do indivíduo em matéria sexual, e cuja declaração foi considerada constitucional; e ainda o caso Bush v. Gore, de 200, que teve por objeto a contagem de votos no Estado da Flórida (USA. SUPREME COURT. 2017). 
No caso acima a Suprema Corte decidiu pela inconstitucionalidade da recontagem de votos na Flórida e que os votos apurados após a recontagem manual não seriam computados, por violar a cláusula de proteção igualitária prevista na Décima Quarta Emenda. Bush, eleito, nomeou o Juiz John Roberts Jr. para presidir a Corte por ocasião da morte de Rehnquist, em 2005. (USA. SUPREME COURT. 2017).

A Corte se caracterizou como ativista, mas com uma vocação objetiva na interpretação das normas constitucionais, o que determinou a valorização da legislação e o seu fortalecimento por meio das decisões jurisprudenciais, sem priorização da Carta de direitos de forma incondicional, conjugando as características da gênese do direito Norte-americano, de tradição da Common Law com o Civil Law. Legislação e jurisprudência passaram a ser o binômio da Corte (WALDRON. 2003. pp.215-231).

\section{CONCLUSÃO}

O termo ativismo na cultura Norte-Americana ora significava a atuação dos juízes em prol do bem estar social, de forma a decidir pela maior proteção dos direitos e liberdades fundamentais, extrapolando o que estava previsto na Constituição, ora representava uma posição jurídica restritiva, em prestígio aos Poderes Legislativo e Executivo, cabendo somente a eles corrigir a lei, ampliá-la ou modificá-la, mas desde que não ferisse os princípios constitucionais que teriam supremacia sobre leis federais e estaduais, e obviamente a repartição de poderes.

O ativismo que foi analisado por Schlesinger revela que, no tocante à história da Suprema Corte Norte-Americana, nem sempre foi ele caracterizado como uma manifestação da proteção dos direitos e liberdades individuais e coletivas, mas uma posição política, como se verifica nos casos Marbury vs. Madison, Dred Scott vs. Sandford; Lochner vs. New York e tantos outros, considerados como precedentes históricos do ativismo judicial.

As decisões nos casos acima mencionados expressam a ideia de construção do direito a partir de casos concretos e que foram submetidos, mediante jurisdição contenciosa, a exame de uma Corte Constitucional, como objetivo de ver a fórmula democrática expressa na constituição resguardada, mas também a necessidade de tornar o Bill of Rights uma realidade, que nem sempre foi alcançada, como no caso Dred Scott vs. Sandford. 
O termo ativismo revela que a sua apropriação pela área jurídica se deu com a necessidade de se criar um bloco de constitucionalidade mínimo que garantisse a elaboração de normas protetivas de direitos humanos e fundamentais; a revogação ou não aplicação de normas incompatíveis com os direitos humanos e as normas internacionais constantes do sistema global de proteção dos direitos humanos e ainda a ação dos juízes em realizar o controle de constitucionalidade das leis, preservando os direitos fundamentais, e o controle de constitucionalidade das leis internacionais, visando compatibilidade entre estas e as normas nacionais.

\section{REFERÊNCIAS}

FINKELMAN, Paul. Dred Scott v. Sandford. The Public Debate Over Controversial Supreme Court Decisions. Melvin I. Urofsky, ed, p. 24-33, 2006.

GREEN, Craig. In An Intellectual History of Judicial Activism (May 27, 2009). Emory Law Journal, Vol. 58, No. 5, p. 1195, 2009; Temple University Legal Studies Research Paper No. 2009-32. Disponível em http://ssrn.com/abstract=1410728. Acesso em 01/05/2015

KMIEC, Keenan D. The Origin and Current Meanings of Judicial Activism. California Law Review (2004): 1441-1477.

LOCKART, William B.; KAMISAR, Yale; CHOPER, Jesse; FALLON JR., Richard. Constitucional Law: Case-Comments-Questions.18 ed. Saint Paul: West.Pub.Co. 996.

McWHINNEY, Edward. Judicial Review in the English-Speaking World.Toronto: University of Toronto Press, 1956, pp. 170/185; HORWITZ, Morton J. The Warren Court and the Pursuit of Justice. New York: Hill and Wang, 1998, p. 114; BURNS, James MacGrecor. Packing The Court. The Rise of Judicial Power and the Coming Crisis of the Supreme Court. New York: Penguin Press, 2009, p. 167.

ROOSEVELT, Franklin D. The public Papers and Adresses of Franklin D. Roosevelt.In: MANCINI, Francesco. Il pensiero politico nell' etá di Roosevelt. Bologna: Il Mulino, 1962.

SCHLESINGER Jr., Arthur M. The Supreme Court: 1947.Fortune Vol. 35 (1), 1947.

SCHWARTZ, Bernand. A book of Legal Lists: The best and worst in American Law. Oxford: Oxford University Press. 1996. pp. 118-119.

SUSTEIN. Cass R. Dred Scott v. Sandford and Its Legacy, in GEORGE, Robert P. Great Cases in Constitucional Law. Princeton University Press: New Jersey, 2000. pp 64-89

TAVARES, André Ramos; ROTHEMBERG, Walter Claudius. Aspectos Atuais do Controle de Constitucionalidade no Brasil: recurso extraordinário e arguição de descumprimento de preceito fundamental Rio de Janeiro: Forense. 2003.

THOMAS REED POWELL ON THE ROOSEVELT COURT John Braeman Professor of History, University of Nebraska-Lincoln. Disponível em 
http://conservancy.umn.edu/bitstream/handle/11299/164983/05_01_Braeman.pdf?sequence=1 \&isAllowed=. Acesso em $1^{\circ}$ de maio de 2015

TRINDADE, André Karam, MORAIS, Fausto Santos de. Ativismo Judicial: As Experiências Norte-Americana, Alemã e Brasileira. Revista da Faculdade de Direito-

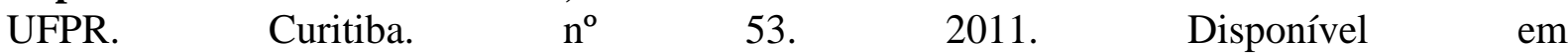
http://ojs.c3sl.ufpr.br/ojs/index.php/direito/article/view/30764. Acesso em 01/10/2015

USA. SUPREME COURT. TROP v. DULLES. Disponível em http://caselaw.lp.findlaw.com/scripts/getcase.pl?court=US\&vol=356\&invol=86. Acesso em 01.05.2017.

US SUPREME COURT. Marbury v. Madison. 5 U.S. 1 Cranch 137 (1803). Disponível em https://supreme.justia.com/cases/federal/us/5/137/case.html. Acesso em 01.05.2017.

USA. SUPREME COURT. Scott v. Sandford, 60 U.S. 393 (1856) Disponível em https://supreme.justia.com/cases/federal/us/60/393/case.html. Acesso em 01.05.2017

USA. SUPREME COURT. Lochner v. New York. 198 U.S. 45 (1905) Disponível em https://supreme.justia.com/cases/federal/us/198/45/case.html. Acesso em 01.05.2017.

USA. SUPREME COURT. Brown v. Board of Education of Topeka: 347 U.S. 483 (1954). Disponivel em https://supreme.justia.com/cases/federal/us/347/483/case.html. Acesso em 01.05.2017.

USA. SUPREME COURT. Baker v. Carr: 369 U.S. 186 (1962). Disponível em https://supreme.justia.com/cases/federal/us/369/186/case.html.Acesso em 01.10.2017.

USA. SUPREME COURT. Gideon v. Wainwright. 372 U.S. 335 (1963) Disponível em https://supreme.justia.com/cases/federal/us/372/335/case.html. Acesso em 01.10.2017.

USA. SUPREME COURT.Reynolds v. Sims: 377 U.S. 533 (1964). Disponível em https://supreme.justia.com/cases/federal/us/377/533/case.html. Acesso em 01.10.2017.

USA. SUPREME COURT. New York Times Co. v. Sullivan. 376 U.S. 254 (1964). Disponível em https://supreme.justia.com/cases/federal/us/376/254/case.html. Acesso em 01.05.2017.

USA. SUPREME COURT. Roe v Wade: 410 US 113 (1973).Disponível em https://supreme.justia.com/cases/federal/us/410/113/case.html. Acesso em 01.05.2015

US SUPREME COURT Bowers v.Hardwick: 478 U.S. 186 (1986).Disponível em https://supreme.justia.com/cases/federal/us/478/186/case.html. Acesso em01.05.2017.

USA SUPREME COURT Bush v. Gore: 531 US 98 (2000).Disponível em https://supreme.justia.com/cases/federal/us/531/98/case.html. Acesso em 01.05.2017

USA. SUPREME COURT. Boumediene v. Bush: 553 US 723 (2008). Disponível em https://supreme.justia.com/cases/federal/us/553/723/opinion.html. Acesso em 01.05.2017

USA. SUPREME COURT. Mugler versus Kansas, 123 U.S. 623 (1887) U.S. Supreme Court. Disponível em https://supreme.justia.com/cases/federal/us/123/623/case.html. Acesso em 01.05.2017 
USA. SUPREME COURT. Lochner v. New York. 198 U.S. 45 (1905) Disponível em https://supreme.justia.com/cases/federal/us/198/45/case.html. Acesso em 01.05.2017.

USA. SUPREME COURT. Brown v. Board of Education of Topeka :: 347 U.S. 483 (1954). Disponível em https://supreme.justia.com/cases/federal/us/198/45/case.html. Acesso em 01.05.2017.

USA. SUPREME COURT. McKeiver v. Pennsylvania 367 U.S. 643 (1961). Disponível em https://supreme.justia.com/cases/federal/us367/643/case.html. Acesso em 01.10.2017.

USA. SUPREME COURT. Fay v. Noia: 372 U.S. 391 (1963):Disponível em https://supreme.justia.com/cases/federal/us/372/391/case.html.Acesso em 01.05.2017.

USA. SUPREME COURT. Gideon v. Wainwright. 372 U.S. (1963). Disponível em https://supreme.justia.com/cases/federal/us/372/335/case.html. Acesso em 01.10.2017.

USA. SUPREME COURT. Miranda v. Arizona :384 U.S. 436(1966). Disponível em https://supreme.justia.com/cases/federal/us/384/436/case.html. Acesso em 01.10.2017.

US SUPREME COURT.Gray v. Sanders :372 U.S. 368 (1963) Justia U.S. Supreme Court Disponível em https://supreme.justia.com/cases/federal/us/372/368/case.html. Acesso em 01.10.2017.

US SUPREME COURT.Reynolds v. Sims: 377 U.S. 533 (1964) Justia U.S. Supreme Court Disponivel em https://supreme.justia.com/cases/federal/us/377/533/case.html. Acesso em $\underline{z 1.10 .2017 .}$

USA. SUPREME COURT. United States v. Mississipi 380 U.S. 520 (1964) Justia U.S. Supreme Court Disponível em https://supreme.justia.com/cases/federal/us/380/520/case.html. Acesso em 01.10.2017.

USA. SUPREME COURT. Bond v. Floyd, 385. U.S. 116 (1966).Disponível em https://supreme.justia.com/cases/federal/us/385/116/case.html . Acesso em 10.05.2017

USA. SUPREME COURT. Baker v. Carr:369 U.S. 186 (1962). Disponível em https://supreme.justia.com/cases/federal/us/369/186/case.html. Acesso em 01.10.2017

USA. SUPREME COURT. Brandenburg v. Ohio: 395 U.S. 444 (1969) Disponível em https://supreme.justia.com/cases/federal/us/395/444/case.html. Acesso em 01.10.2017.

USA. SUPREME COURT. Bowers v. Hardwick: 478 U.S. 186 (1986).Disponível em https://supreme.justia.com/cases/federal/us/478/186/case.html. Acesso em 01.05.2017.

VAISSE, Maurice. As relações Internacionais desde 1945. Reimp. Edições 70. Lisboa: Biblioteca Nacional de Portugal 70. 2009.

WALDRON, Jeremy. A dignidade da Legislação. Trad. De Luís Carlos Borges. São Paulo: Martins Fontes, 2003.

WOLFE, Christopher. The rise of modern judicial review. From constitucional interpretation to judge-made law. Boston: Littlefield Adams Quality Paperbacks.1994. 